\title{
A Review of Leadership Styles and Employee's Well- being in Different Types of Organizations
}

\author{
Muhammad Jufri \\ Universitas Negeri Makassar \\ Makassar, Indonesia
}

\author{
Hillman Wirawan \\ Universitas Hasanuddin \\ Makassar, Indonesia
}

\begin{abstract}
This paper is a viewpoint paper and it aims at presenting theoretical-based evidence on the role of leadership styles and employee's well-being. First, the authors provided a review in the area of leadership styles (i.e., transformational and transactional styles) and well-being. Second, extensive reviews were also included to support the arguments before generating theoretical-based conclusions. This paper suggested that transformational leadership style outperformed the effect of transactional leadership style on employee's well-being. In addition, different types of organizations potentially moderate the relationship between the variables. Future study should conduct an empirical investigation to further understanding the relationships.
\end{abstract}

Keywords-leadership; transformational; transactional; wellbeing; organization

\section{INTRODUCTION}

Employee well-being is paramount in maintaining work productivity and human resources planning in the organization [1]. On the other hand, the leadership also affects the variability of employee life, including the employee's wellbeing. Nielsen \& Munir reported the associations between positive leadership behavior (e.g., transformational leadership) and employee well-being [2]. This indicates that leadership style has a significant contribution to the well-being of an organization [3]. It is important to understand more about the effect of certain leadership style for the employee well-being.

Basically, leadership style used by a leader in order to deal with problems or situations. The leader is a position which has an important role in an organization required the responsibility on planning, organizing, coordinating, directing and controlling the organization. Thus, leadership is subject to implementation to achieve organizational goals and to deal with various situations that arise in organizational conditions. Moreover, Leaders use their leadersip style each in handling various conditions There are two leadership styles examined in this paper; the transformational and transactional leadership. Both transformational and transactional leadership style predict the variability of employee well-being. A systematic review provides a better insight in understanding the role of leadership styles on employee well-being. This paper has initiated the first step to exploring the role of leadership style on employee's well-being particularly in the different type of organization.

\section{RESEARCH METHOD}

This paper employed a non-empirical method, and it aimed at reviewing some basic literature in the area of leadership styles and employee well-being. There were three fundamental steps in presenting viewpoints in this paper. First, the authors reviewed some basic literature and current research in the area of leadership styles. Second, the authors also reviewed literature in the area of employee's well-being. Last, the authors reviewed the relationship between the leadership styles and employee's well-being as well as presenting arguments and future research directions.

\section{RESULTS AND DISCUSSION}

\section{A. Leadership Styles}

The leadership is a core factor that contributes immensely to the well-being of organizations and nations, specifically the two styles of leadership - transformational and transactional leadership [3]. Two of the most prominent leadership theories are transformational and transactional leadership style [4], [5]. The transformational leadership can increase the level of employee's motivation, morale, and performance in a variety of mechanisms such as the way a leaders instill a meaning during the regular work day [6]-[8]. These include connecting and facilitating the employee's self and identity to the organization, inspiring and make employees interested with a good role model and, challenging employees with a sense of belonging of works, and considering the strengths and weaknesses of employees [9]-[11].

Besides, the other type of leadership style is transactional leadership. Transactional leadership as the leaders, who apply contingent reward, management-by-exception (active), and management-by-exception (passive) [12], [13]. They also suggest that transactional styles focus more on applying the principle of rewards and punishment. If followers or employees do what is expect of them, then they are rewarded and punished when they do not perform on the job as expected.

\section{B. Employee well-being}

Subjective well-being (SWB) comprises the scientific analysis of how people evaluate their lives (current and past live event). These evaluations include people's emotional 
reactions to particular events, moods, and judgments of their life satisfaction, fulfillment, and satisfaction with domains such as family and work [14]. Chen et al. found that the results from the bifactor model study of well-being confirmed that Psychological Well-Being and Subjective Well-Being were two related constructs [15]. This finding provided support for the notion that PWB and SWB were conceptually related to constructing.

The PWB and SWB are not the only constructs of wellbeing. Young \& Bhaumik utilized the construct of employee's Mental Well-Being [16]. This construct covered both subjective well-being and psychological functioning, in which all items were worded positively and addressed aspects of positive mental health. Employee's well-being can also be seen as subjective or occupational well-being [17]. Moreover, Wright \& Huang postulated the significant role of well-being on employee job performance, retention, and cardiovascular health [1]. Related to this discussion, Ed et al. assessed several demographic variables that can affect the level of well-being such as income, relationship, age, health, gender, the level of education, type of job, and intelligence might determine the level of employee's well-being [18].

\section{The effect of leadership styles and organization types on employee well-being}

The transformational leadership has been linked to more positive employee emotions during the workday [19]. Similarly, Skakon et al. reported associations between positive leadership behavior (e.g., transformational leadership) and employee well-being, which were based mainly on crosssectional analyses [20]. Kara et al. also suggested that transformational leadership had a significant positive influence on employee well-being [21]. In a recent study, also there was a significant and positive relationship between transformational leadership and employee's psychological well-being [2], [21], [22]. As a result, the more likely a leader has a transformational style, the higher the employee wellbeing.

In contrast, Javeed \& Farooqi conducted research in Pakistan and attested the relationship between transformational leadership and employee's well-being [23]. Javeed \& Farooqi argued that different culture or work condition might moderate the effect of the relationship as employees might perceive work condition differently [23]. This causes the insignificant effect of transformational leadership on employees' well-being. On the other hand, the transactional style also influences employees' performance [24]. Unfortunately, the relationship between transactional leadership and employees' work life is more likely negative than positive [21].

Regarding organizational types and employees well-being, employees in public and private sector experience similar management practices and outcomes [25]. However, Kelloway et al. found that only transformational leadership style that had a positive contribution to the employee well-being [22]. Regardless the effect of leadership styles on well-being, transformational leadership outperforms the transactional leadership even though both still contribute significant effect to performance.

This paper suggested three main points; 1) the transformational leadership style has a greater effect on employee's well-being over the transactional style. However, certain organizational types also contribute to employee wellbeing. 2) Different types of organization or context potentially predict employee's well-being. 3) Different types of organizations potentially moderate the correlation between the leadership styles and employee's well-being. Albeit previous findings have supported the ideas, the further empirical study is necessary to attest these conclusions.

\section{CONCLUSION}

This study found that together task commitment and teacher's quality of teaching had an important role in determining teacher's work satisfaction. Task commitment and teacher's quality of teaching were two highly performance-related variables to teaching. This suggests that teachers' work satisfaction is greatly influenced by their task commitment and their quality of teaching.

\section{REFERENCES}

[1] T. A. Wright and C. Huang, 'The many benefits of employee well- being in organizational research', J. Organ. Behav., vol. 33, no. 8, pp. 1188-1192, 2012.

[2] K. Nielsen and F. Munir, 'How do transformational leaders influence followers' affective well-being? Exploring the mediating role of selfefficacy', Work Stress, vol. 23, no. 4, pp. 313-329, 2009.

[3] J. A. Odumeru and I. G. Ogbonna, 'Transformational vs. transactional leadership theories: Evidence in literature', Int. Rev. Manag. Bus. Res., vol. 2, no. 2, p. 355, 2013.

[4] M. R. W. Hamstra, N. W. Van Yperen, B. Wisse, and K. Sassenberg, 'Transformational-transactional leadership styles and followers' regulatory focus', J. Pers. Psychol., 2011.

[5] P. Bycio, R. D. Hackett, and J. S. Allen, 'Further assessments of Bass's (1985) conceptualization of transactional and transformational leadership.', J. Appl. Psychol., vol. 80, no. 4, p. 468, 1995.

[6] E. A. Landis, D. Hill, and M. R. Harvey, 'A synthesis of leadership theories and styles', J. Manag. Policy Pract., vol. 15, no. 2, p. 97, 2014.

[7] D. N. Hartog, J. J. Muijen, and P. L. Koopman, 'Transactional versus transformational leadership: An analysis of the MLQ', J. Occup. Organ. Psychol., vol. 70, no. 1, pp. 19-34, 1997.

[8] A. Humphrey, 'Transformational leadership and organizational citizenship behaviors: The role of organizational identification', Psychol. J., vol. 15, no. 4, pp. 247-268, 2012.

[9] J. Antonakis, F. Marika, and S. Liechti, 'Learning Charisma', Harv. Bus. Rev., vol. 90, no. 6, pp. 127-130, 2012.

[10] P. Jacquart and J. Antonakis, 'When does charisma matter for top-level leaders? Effect of attributional ambiguity', Acad. Manag. J., vol. 58, no. 4, pp. 1051-1074, 2015.

[11] J. Antonakis, 'Transformational and charismatic leadership', Nat. Leadersh., vol. 41, no. 0, pp. 256-288, 2012.

[12] B. M. Bass and R. M. Stogdill, Bass \& Stogdill's handbook of leadership: Theory, research, and managerial applications. Simon and Schuster, 1990.

[13] B. J. Avolio and B. M. Bass, 'Multifactor leadership questionnaire (MLQ)', Mind Gard., 2004.

[14] E. Diener, S. Oishi, and R. E. Lucas, 'Personality, culture, and subjective well-being: Emotional and cognitive evaluations of life', Annu. Rev. Psychol., vol. 54, no. 1, pp. 403-425, 2003. 
[15] F. F. Chen, Y. Jing, A. Hayes, and J. M. Lee, 'Two concepts or two approaches? A bifactor analysis of psychological and subjective wellbeing', J. Happiness Stud., vol. 14, no. 3, pp. 1033-1068, 2013.

[16] V. Young and C. Bhaumik, Health and well-being at work: A survey of employees. Department for Work and Pensions Sheffield, 2011.

[17] F. D. Bretones and M. J. Gonzalez, 'Subjective and occupational wellbeing in a sample of Mexican workers', Soc. Indic. Res., vol. 100, no. 2, pp. 273-285, 2011.

[18] D. Ed, E. M. Suh, R. E. Lucas, and H. L. Smith, 'Subjective well-being: Three decades of progress', Psychol. Bull., vol. 125, no. 2, pp. 276-302, 1999.

[19] T. A. Judge, C. J. Thoresen, J. E. Bono, and G. K. Patton, 'The job satisfaction-job performance relationship: A qualitative and quantitative review.' American Psychological Association, 2001.

[20] J. Skakon, K. Nielsen, V. Borg, and J. Guzman, 'Are leaders' wellbeing, behaviours and style associated with the affective well-being of their employees? A systematic review of three decades of research', Work Stress, vol. 24, no. 2, pp. 107-139, 2010.

[21] D. Kara, M. Uysal, M. J. Sirgy, and G. Lee, 'The effects of leadership style on employee well-being in hospitality', Int. J. Hosp. Manag., vol. 34, pp. 9-18, 2013.

[22] E. K. Kelloway, N. Turner, J. Barling, and C. Loughlin, 'Transformational leadership and employee psychological well-being: The mediating role of employee trust in leadership', Work Stress, vol. 26, no. 1, pp. 39-55, 2012.

[23] T. Javeed and Y. A. Farooqi, 'Impact of transformational leadership style on employees' satisfaction and well-being with working conditions as mediator', Int. J. Multidiscip. Sci. Engagem., vol. 4, no. 7, pp. 1-8, 2013.

[24] E. I. Ejere and U. D. Abasilim, 'Impact of transactional and transformational leadership styles on organisational performance: empirical evidence from Nigeria', J. Commer., vol. 5, no. 1, pp. 30-41, 2012.

[25] L. Brown and J. R. Barnett, 'Is the corporate transformation of hospitals creating a new hybrid health care space? A case study of the impact of co-location of public and private hospitals in Australia', Soc. Sci. Med., vol. 58, no. 2, pp. 427-444, 2004. 